\title{
Hydraulic Analysis of Storm Diversion System (SDS) of Hatirjheel Begunbari Lake of Dhaka City
}

\author{
Lamisa Malik and M. Abdul Matin
}

\begin{abstract}
This paper deals with the hydraulic analysis of storm diversion system (SDS) of Begunbari-Hatirjheel lake project of Dhaka city, Bangladesh. For analyzing behavior of pipe system hydraulic modeling software, Sewer CAD has been used. Analysis has been done for both dry season and wet weather flow conditions. Different gated conditions such as, full and partially full pipe flow have also been considered in hydraulic analysis. Inflow storm peak discharge has been calculated using rational method. Dry weather condition has been analyzed using design data which represents the present operating condition of diversion system. It reveals that the wet season peak flows in pipes undergo highly supercritical with high turbulence and backflow. It is hoped that the storm flow hydraulic analysis presented in this paper will manifest an idea about the post project flow behavior in the sewer for both extreme and minimum flow condition.
\end{abstract}

Index Terns-Dry weather flow, Hatirjheel lake, Sewer CAD, specific energy, storm diversion system.

\section{INTRODUCTION}

Dhaka city which used to have an excellent natural drainage system even 40 years ago has been degraded by the elapsed time due to various changes in the topography, land use, pollution and interventions. In order to prevent pollution, remove water logging, and to improve water quality condition of the entire wetlands DWASA has planned to take up a project that would divert all the domestic \& industrial wastewater that are being discharged into the Buriganga-Hatirjheel area. Hatirjheel-Begunbari the integrated development project has implemented through construction of large diameter diversion sewers running along the southern and northern peripheries of the project area with a view to improve the dreadfully degraded environment, to protect the wetlands and to alleviate of traffic congestion.

Drainage system of Dhaka city is a wide matter of concern. There have been studies on it extensively for several years like flood management and vulnerability of Dhaka city, effect of urbanization on storm runoff characteristics of Dhaka city causes and effects of water logging in Dhaka city, application of numerical model for drainage improvement of Dhaka-Narayanganj-Demra (DND) area of Dhaka city. Hydraulic behavior of storm diversion structure (SDS) in a laboratory model under various flow conditions has been investigated by Matin and Rahman [1]. Assessment of drainage capacity and navigability of khals of the eastern part of Dhaka city connecting to Balu river has been done by

Manuscript received October 9, 2015; revised December 29, 2015.

The authors are with Bangladesh University of Engineering and Technology, Bangladesh (e-mail: lamisa_malik@yahoo.com).
Matin et al. [2] by using HEC-RAS. For the storm water drainage and navigational purposes of the greater Dhaka city study on storm water drainage system improvement project in Dhaka city was carried out by JICA (1990) to prepare phase program of the flood protection and internal drainage improvement project for the developed areas in Dhaka city and to identify the major priority areas.

Considering importance of developing drainage system in Dhaka city and effect of Hatirjheel Begunbari project during monsoon and dry period, hydraulic analysis of storm diversion pipes of the project has been carried out [3] and presented in this paper.

\section{STUdy AREA AND STORM SEWER LAYOUT}

Hatirjheel-Begunbari the integrated development project was developed through connecting the east-west link missing link from Tongi diversion road to Pragati Shwarani. The project is being implemented jointly by RAJUK of the Ministry of Housing and Works, and DWASA and LGED of the Ministry of Local Government, Rural Development and Cooperatives. The entire site covers an area of 302 acre. During dry season, the storm sewers mostly carry significant flows of domestic sewage as well as industrial wastewater. The unprocessed domestic sewage and industrial wastewater drains through this low land through the Begunbari khal-Norai khal into the Balu River. The Balu river ultimately discharges into the Sitalakhya river. During monsoon, the pollution level drops to some extent due to dilution of domestic sewage and industrial effluent by stormwater.

TABLE I: STORM SEWER OUTFALL LOCATION AND DISCHARGE IN DRY SEASON [4]

\begin{tabular}{|c|c|c|}
\hline $\begin{array}{c}\text { Outlet } \\
\text { Identification } \\
\text { No. }\end{array}$ & Location & $\begin{array}{c}\text { Dry Season } \\
\text { Discharge } \\
\left(\mathbf{m}^{\mathbf{3}} \mathbf{s} \mathbf{)}\right.\end{array}$ \\
\hline Q1 & Lowland behind Sonargaon Hotel & 1.73 \\
\hline Q2 & East of Tongi diversion road & 0.28 \\
\hline Q3 & $\begin{array}{c}\text { Storm sewer coming from Karwan } \\
\text { Bazar area and discharging into the } \\
\text { lowland behind Sonargaon Hotel at the } \\
\text { entrance of BGMEA building }\end{array}$ & 0.2 \\
\hline Q4 & $\begin{array}{c}\text { Storm sewer coming from Tejgaon area } \\
\text { and discharging immediately to the east } \\
\text { of Tongi diversion road }\end{array}$ & 0.14 \\
\hline Q5 & Modhubagh, Nayatola & 0.11 \\
\hline Q6 & Niketon outfall & 1.08 \\
\hline Q7 & $\begin{array}{c}\text { Outfall on the southern side of Rampura } \\
\text { bridge }\end{array}$ & 0.31 \\
\hline Q8 & storm sewer from Badda & 0.48 \\
\hline Q9 & $\begin{array}{c}\text { outfall on the northern side of Rampura } \\
\text { bridge }\end{array}$ & 0.11 \\
\hline
\end{tabular}

Area behind Sonargaon Hotel \& Hatirjheel are widely used by surrounding localities for disposal of domestic wastewater. 
Storm water from surrounding locality also drains into the project lowland, either following natural slope or through temporary drainage pipes and small channels. These are in addition to large volume of storm water that the area receives through the major storm sewage. But Hatirjheel was designed so that only rain water enters into the lake by Pathapath box culvert as one objective of the project was the retention of rainwater but at present, along with rainwater, solid wastes are also entering the lake. total 9 major outfalls discharging into the project lowlands. Among these 6 are major storm sewer and 2 major outlets discharging mainly industrial wastewater.

\section{HYDRAULIC ANALYSIS}

\section{A. General}

Hydraulic modeling software, Sewer CAD has been used for analyzing behavior of pipe system which is an extremely powerful program for the design and analysis of gravity flow and pressure flow through pipe networks and pumping stations. SewerCAD is a deterministic model in which loads are the sources of flow in the sanitary sewer system The model calculates gravity pipe network using the built-in numerical model, which utilizes both the direct step and standard step gradually varied flow methods. It also has the flexibility to mix gravity and pressure components freely, building systems in parallel or in series as they exist in the field ${ }^{[5] . ~ H y d r a u l i c ~}$ analyses are mainly computation for Hydraulic Grade Line (HGL) and Energy Grade Line (EGL) of the sewer system under different flow condition. Head loss due to fluid shear at the pipe wall i.e. pipe friction is calculated using Darcy-Weisbach Equation and Manning's Equation. All these computations are done in each nodal point.

The analysis made on storm diversion system of Begunbari Hatirjheel project is purely hydraulic based. At first thedata obtained for dry season flow from BIWTA-BUET is analyzed as a steady state system to obtain different parameters. As there was no discharge data available for wet season flow, rational method is applied for estimating peak flow. Analyses are also performed for different water level condition such as full flow, half flow, three quarter flow and quarter flow inside circular pipe. In this case pipe discharge is determined using geometric properties which are defined entirely by the geometry of the section and depth of flow of the circular pipes.

\section{B. Model Set up}

Model has been set up for 7 different pipe line segments. Flow from Q1 (Fig. 1) outfall discharges near Rampura bridge. This long division consists of total 58 manholes and 59 pipes [4]. Manholes and pipes are designated with reference to the main plan of the project (Fig. 1). It is subdivided into 3 segments and fed into Sewer CAD.

- Segment 1: CSO to manhole \#25S

Pipe \#1 to pipe \#25

- Segment 2: Manhole \#25S to manhole \#49S

Pipe 26 to pipe 49

- Segment 3: Manhole \#49S to manhole \#58S

Pipe \#50 to pipe \#59

The storm sewer outfall coming from the Karwan Bazar area and discharging into the project lowlands at a location in front of the entrance of the BGMEA building (Q3) has total 13 pipes 13 manhole and an outlet for discharge. This short division is termed as segment 4.

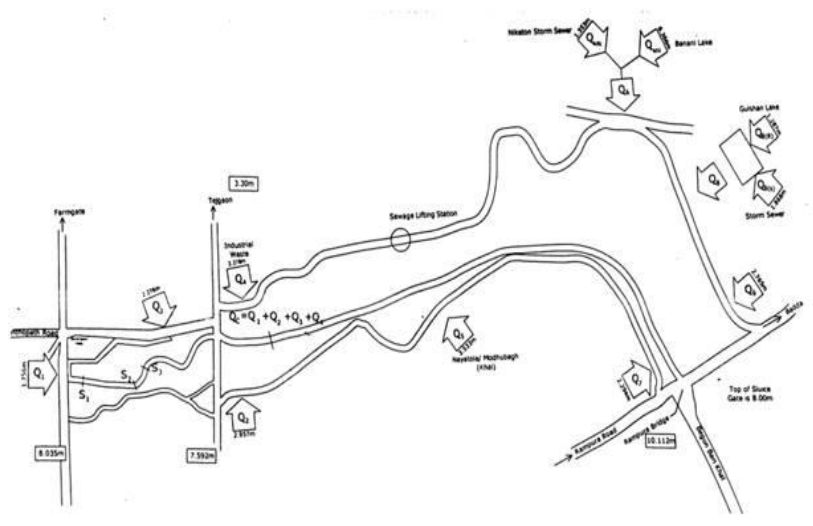

Fig. 1. Major outfalls along the periphery of Hatirjheel project [1]

Storm sewer outfall (Q4) coming from the north and discharging into Hatirjheel immediately to the east of Tongi diversion road. This sewer carries a part of industrial discharges from Tejgaon industrial area. This is denoted as the $3^{\text {rd }}$ division. This long division consists of total 67 manholes and 66 pipes. It is subdivided into 3 segments and fed into SewerCAD.

- Segment 5: CSO to manhole \#37N

Pipe \#73 to pipe \#97

- Segment 6: Manhole \#37N to manhole \#61N

Pipe \#98 to pipe \#122

- Segment 7: Manhole \#61N to manhole \#79N

Pipe \#124 to pipe \#141

\section{Analysis and Results}

\section{1) Dry weather}

Estimation of dry weather flow through the major outfalls is based on the hydraulic capacity of the main diversion sewers. For dry weather analysis, at first model is set up for discharge for $1.73 \mathrm{~m}^{3} / \mathrm{s}$ of discharge from Q1 outlet first. In steady state mode the model is run.

The result obtained from Sewer CAD is used further for analyzing and comparing flow behavior through different pipes. Energy and hydraulic grade line has been plotted which shows the change in energy and velocity head for pipe flow with change of length of the pipe. Hydraulic grade line (HGL) and energy grade line (EGL) for segment 1 for dry weather flow is presented in Fig. 2.

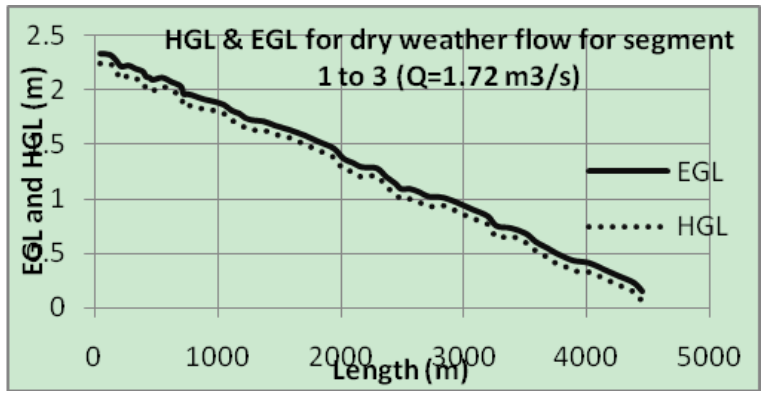

Fig. 2. Hydraulic and energy grade line for dry weather flow for segment 1 to 3 .

Froude number of pipe \#1, 0.63 is calculated from results 
of analysis of dry weather flow. Similarly Froude numbers for other pipes in dry period shows flow is subcritical (Fig. 3); this means flow is tranquil and there is no possibility of hydraulic jump and backwater effect. Flow profile for division 1 is M2, which means bottom of the channel at the downstream end is submerged to a depth less than its normal depth.

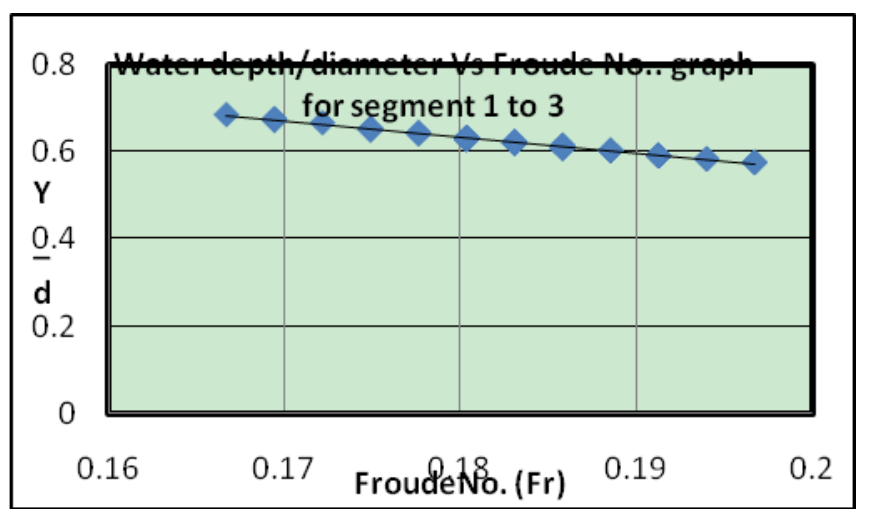

Fig. 3. Relationship between Froude number and ratio of depth of flow to diameter of pipes for dry weather flow.

Ratio of Input discharge to capacity discharge is plotted to show discrepancy of flow form capacity of the pipe. Fig. 4 indicates that for dry weather flow is almost ten times less than its capacity.

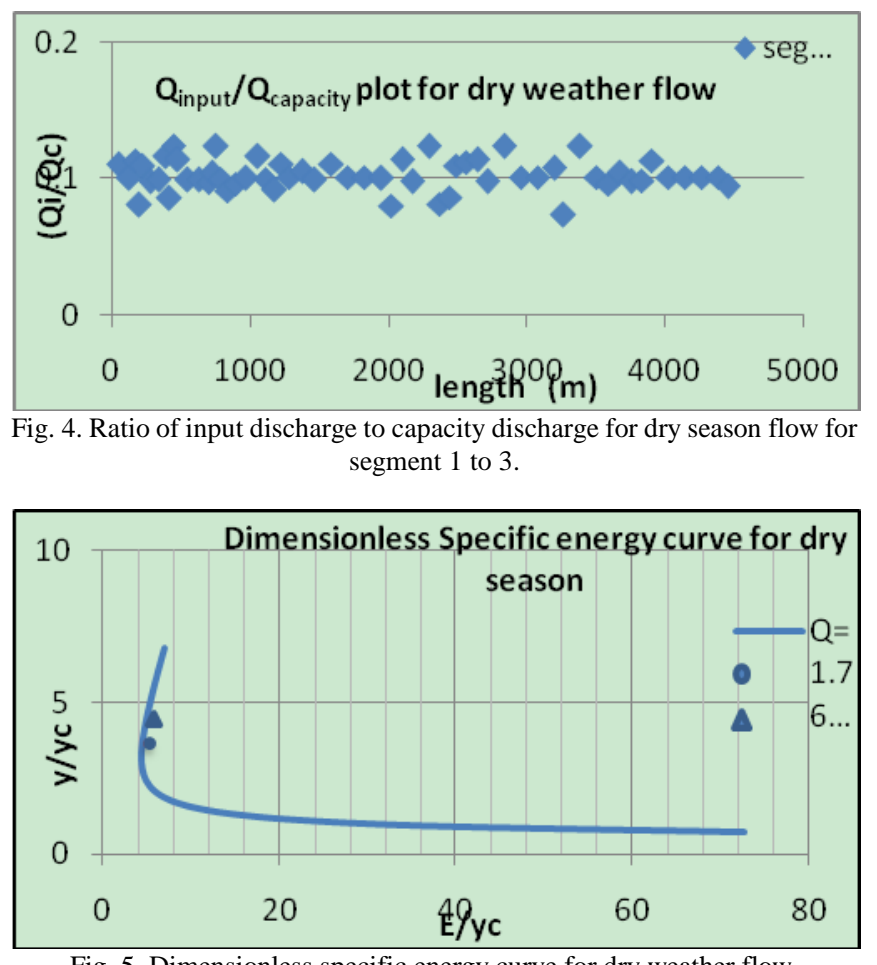

Fig. 5. Dimensionless specific energy curve for dry weather flow.

Another way to evaluate flow problem is to develop the dimensionless form of specific energy diagram. This curve can be used for assessing flow depth and corresponding energy. As the pipe flow is not accessible this study may be used for understanding flow behavior for different discharge condition.

Dimensionless specific energy curve [6] has been generated as shown in Fig. 5. The actual dimensionless parameter of pipe \# 1 and Pipe \# 47 has been shown in this figure. It is seen that actual values for both pipes is subcritical in nature. Using this figure flow characteristics of other pipes can be assessed. Since the discharge during dry weather is very little, all pipes indicate subcritical condition.

\section{2) Flow in pipe during full, half, quarter and three} quarter water depth

Hydraulic analysis is also performed when water flows in pipe at depth is equal to the diameter of the pipe, i.e. full flow; half of the diameter of pipe, i.e. half flow; quarter of pipe diameter, i.e. $1 / 3$ flow and three quarter of diameter of pipe is 3/4 flow. The Manning equation is used for uniform flow calculation for such conditions in a pipe. Cross-sectional area, wetted perimeter, and hydraulic radius for flow of a specified depth in a pipe of known diameter is calculated, thus placing them into Manning's equation discharge is obtained.

Average pipe slope 0.0005 is taken as S value in Manning's equation and Manning's roughness coefficient is taken as 0.013 for concrete pipes.

TABLEII: DISCHARGE OBTAIN FOR PIPE FLOW

\begin{tabular}{|c|c|c|c|}
\hline Pipe Size $(\mathrm{mm})$ & $\begin{array}{c}2 \mathrm{X} 1830= \\
3660\end{array}$ & 1524 & 1200 \\
\hline Full flow $\left(\mathrm{m}^{3} / \mathrm{s}\right)$ & 17.06 & 1.643 & 0.870827 \\
\hline Half flow $\left(\mathrm{m}^{3} / \mathrm{s}\right)$ & 8.527 & 2.807281 & 0.435516 \\
\hline $\begin{array}{c}\text { Quarter flow } \\
\left(\mathrm{m}^{3} / \mathrm{s}\right)\end{array}$ & 2.3362 & 0.2265 & 0.118 \\
\hline $\begin{array}{c}\text { Three quarter flow } \\
\left(\mathrm{m}^{3} / \mathrm{s}\right)\end{array}$ & 15.55 & 1.51 & 0.58 \\
\hline
\end{tabular}

Grade lines for different water depth conditions are plotted (Fig. 6) for comparing water levels and energy of flow in different situation. Energy of flow decreases with distance due to frictional loss and also with decrease of water level within the pipes.

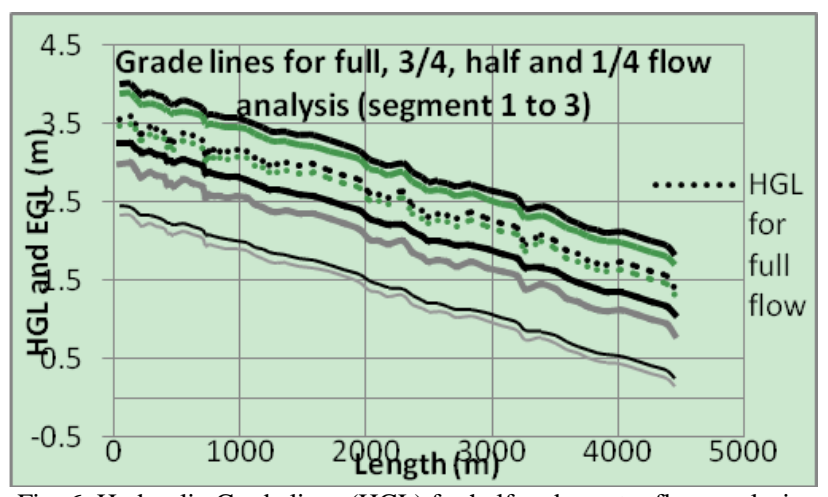

Fig. 6. Hydraulic Grade lines (HGL) for half and quarter flow analysis.

Using these four different water levels inside the pipe system Froude Number is again calculated and it is seen that flow is subcritical throughout system except for sharp drop in elevation near segment 5 to 7 near Banani Lake which is due to presence of syphon duct near underpass.

\section{3) Wet weather flow}

Severe rainfall behavior of these sewer pipes and their response to heavy rainfall is simulated and analyzed in this thesis. Rational formula for peak flow calculation is used for generation of peak flow during rainy season. This peak discharge is used for analyzing pipe condition during rainy season. Severe rainfall behavior of these sewer pipes and their response to heavy rainfall is condition during rainy season. The rational method estimate peak flows, based on the size and runoff coefficient of a watershed, and the intensity of the 
storm event. Area of watershed is determined with the help of Google Earth Pro version. Drainage area and the capacity has been estimated and reported in Matin et. al [2]. Thus total drainage obtained area using Google Earth Pro is $15.266 \mathrm{~km}^{2}$. For commercial and industrial area rational coefficient $(\mathrm{C})$ is assumed to be equal to 0.65 Since areas near Hatirjheel and Begunbarikhal is densely populated commercial area, value of ' $\mathrm{C}$ ' is assumed to be 0.65 for determining peak discharge [5].

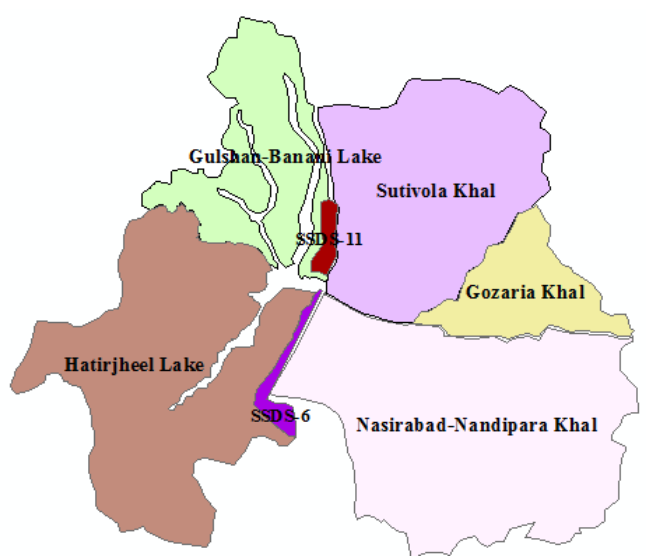

Fig. 7. Map of drainage system of Dhaka city [5].

Recently [7] available analyses have been utilized to get the value rainfall intensity and thus IDF curve has been prepared. For determination of intensity of rainfall help is taken from IDF curve prepared by A. Rana and Faisal Ahammed (April 2013).

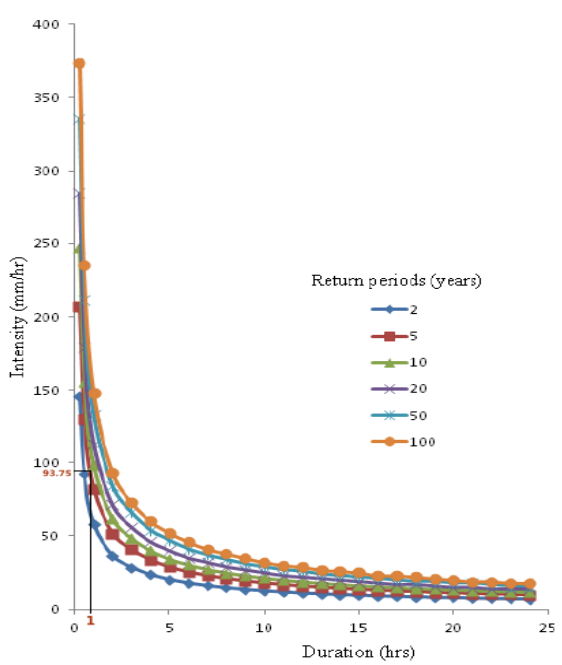

Fig. 8. IDF relationships of Dhaka city [7].

For determining peak discharge value of intensity of rainfall is taken correspond to 1 hour duration and 5 years return period, which is equals to $93.76 \mathrm{~mm} / \mathrm{hr}$, keeping in mind that installations of hydraulic structures considering 100 year average recurrence interval (ARI) situation could be expensive and hence, idealized ARI values 5 or 10 years are feasible to adopt. Obtained peak discharge value is 258.40 $\mathrm{m}^{3} / \mathrm{s}$. After placing this value as known load in SewerCAD, model is made to run in the same procedure as stated in dry weather analysis situation.

Result of analysis shows that during rainy season for intense rainfall condition flow are supercritical with high turbulence and backflow. More than $90 \%$ overflow needs to be allowed through the overflowing gates for all pipes to ensure safety of structure. Flow profiles for most of the pipes are in extreme pressurized condition. Total flow is very high and it is almost 10 to 20 times than its capacity for larger diameter pipes and much more than that for smaller diameter pipes. Depth of flow is greater than the diameter of pipe which will cause intense pressure on pipe wall and if flow is not allowed to overflow through gates it would cause devastating result including breakage and failure of pipes. It may cause flood in surrounding areas and backflow.

Variation in HGL in wet weather analysis ranges between 3000 and 7 meters and variation in EGL ranges between 5600 to 38.9 meters. Graphs of energy and hydraulic grade lines show erroneous value due to high pressure and turbulence. Since the boundary condition provided in the model cannot tolerate this extreme discharge.

Relations with Froude number, input discharge to capacity discharge ratio serve as an important reference for assessing flow behavior and effect of heavy rainfall on pipe system. Fig. 9 shows decreasing relationship of depth diameter ratio with increasing value of Froude number for first three segments. However, Froude number increases with increase of flow depth within circular pipe.

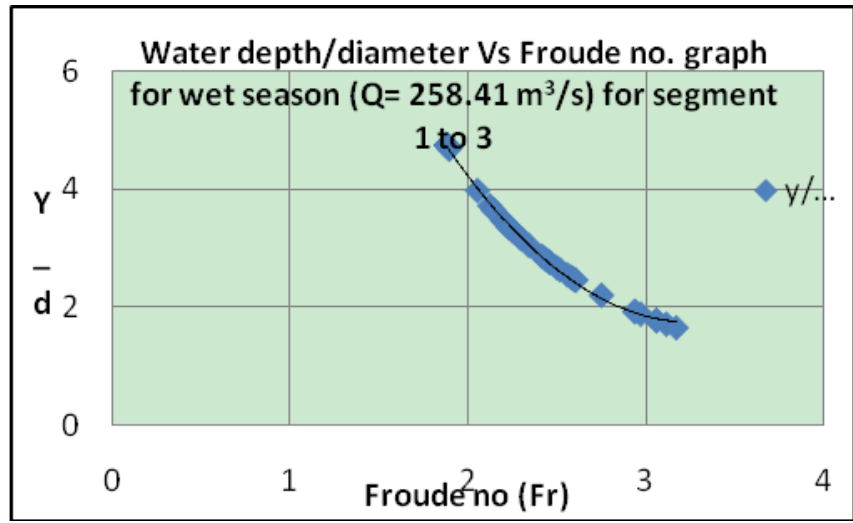

Fig. 9. Relationship between Froude number and ratio of depth of flow to diameter of pipe for wet weather flow.

Value of Froude number is observed to be within 4.1 to 0.94 for during wet condition analysis. Greater value from unity for Fig. 10 indicates pipe flow during analysis exceeds the capacity of pipeline.

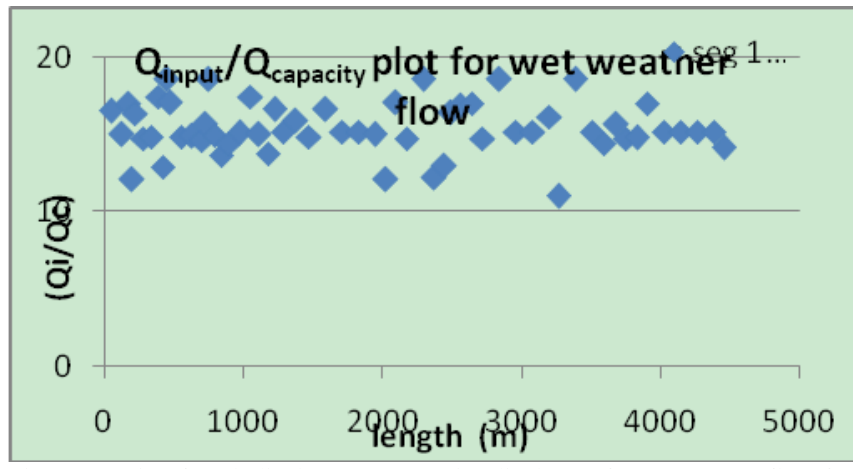

Fig. 10. Ratio of peak discharge to capacity discharge for wet season flow for segment 1 to 3

Dimensionless energy value for pipe \#1 is 75.15 for wet season flow corresponding to actual depth to critical depth ration value 17.11 . It indicates abnormally high value beyond the capacity of design pipeline system. To prevent devastating 
condition from being occurred gate should be opened properly to pass excess discharge. Input discharge to capacity discharge ratio for wet weather analyses shows graphically that input discharge is ten to twenty times of its capacity for segment 1 to 3 .

\section{Field Measurments}

Dry weather flow depth through the pipe has been measured to observe the post project hydraulic condition of the diversion system. Water depths water measured in Ten manhole of the pipe segment1. Measured water depths are found to be range within $1.2 \mathrm{~m}$ to $1.3 \mathrm{~m}$ for the segment 1 .

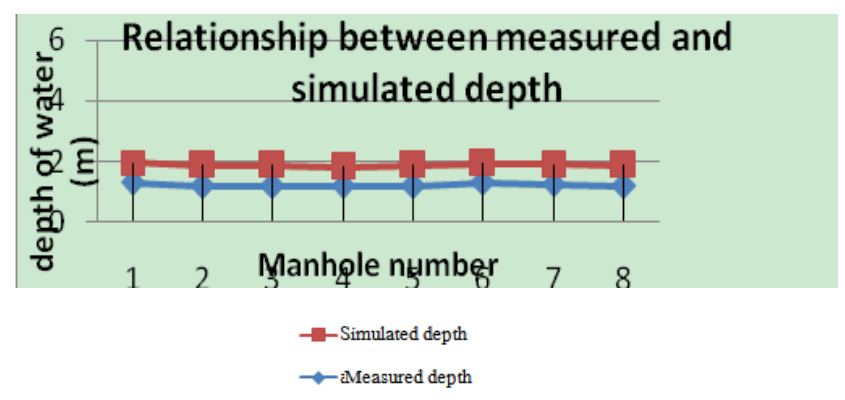

Fig. 11. Simulated and measured water depth on same scale.

Actual water depth measured in the field during dry season and determined water depth by using Sewer CAD for dry weather analysis are plotted on same graph Fig. 11. Discrepancy in depth between actual and model value ranges between 0.64 to $0.52 \mathrm{~m}$. Measured water depth is less than model simulated water depth. Discharge which has been used in the model for simulation was obtained during pre-project condition. At post project situation total discharge (Q1) is divided into two part (Fig. 1) giving lower value of water depth than previously existed.

\section{Discussions ON RESUlts}

Model has been set for entire storm diversion system of Begunbari Hatirjheel project for three different options. The options are: Dry weather flow (see Table I) $\left(Q=1.73 \mathrm{~m}^{3} / \mathrm{s}, 0.2\right.$ $\left.\mathrm{m}^{3} / \mathrm{s}, 0.142 \mathrm{~m}^{3} / \mathrm{s}\right)$; Wet season flow $\left(Q=258.41 \mathrm{~m}^{3} / \mathrm{s}\right)$; Flow in different water depth inside the pipe (see Table II) (full flow $Q=17.06$ to $0.87 \mathrm{~m}^{3} / \mathrm{s}$, three quarter flow $Q=15.55$ to $0.58 \mathrm{~m}^{3} / \mathrm{s}$, half flow $Q=8.52$ to $0.43 \mathrm{~m}^{3} / \mathrm{s}$ and quarter flow $Q=$ 2.34 to $0.12 \mathrm{~m}^{3} / \mathrm{s}$ ).

Variation of hydraulic parameters like, velocity, depth of water, headloss has been calculated for different discharges. For example, values of average velocity vary between 2 to $0.85 \mathrm{~m} / \mathrm{s}$ for dry weather flow, 3.6 to $0.85 \mathrm{~m} / \mathrm{s}$ for different flow depth within the pipe. For wet weather flow such velocities are found to be extremely high and not practicable.

Hydraulic grade line (HGL) and energy grade line (EGL) of pipe line systems have been plotted (Fig. 2 and Fig. 6). From these figures the changes in velocity head for different pipe can be realized. For example, variation in HGL in dry weather ranges between 2.89 to 0.1 meters and EGL ranges between 2.91 to 0.12 meters. For severe rain condition analysis, flow is very high and it is higher than ten times than its capacity and value of velocity head is higher than $30 \mathrm{~mm}$.

Froude number has been calculated using the hydraulic parameters obtained from the model. The values indicate that, flow remains mainly subcritical during the dry season (Fig. 3) and varies within 0.67 to 0.30 . For high discharge flow condition is supercritical and value of Froude number generally remains within 4.1 to 0.94 (Fig. 9). Thus it is suggested that overflow gates must be kept open during this heavy storm runoff situation.

This study is a preliminary analysis using Sewer CAD. However, other hydraulic and storm sewer model like, Sewer GEMS, SWMM, MOUSE can be applied for further analyzes of pipe network. Measurement on field has been done for few pipes. More field data i.e. velocity, water depth in manholes, discharge in inlet will be required for further analysis of flow behavior and verification of the model. Analysis of Inflow for dry weather flow and adequacy check of storm diversion structures can also be performed using hydraulic model.

\section{CONCLUSIONS}

Dimensionless specific energy curve for the newly constructed storm diversion system of Hatirjheel Begunbari lake project of Dhaka city has been generated. This curve will be used for assessing flow depth and corresponding energy. Dimensionless energy value for pipe- 1 is 4.7 for dry season and 75.15 for rainy season flow. Comparison between input flow in pipe and total capacity of the pipe has been made. Discrepancy ratio (input flow to capacity)indicates whether the pipe is pressurized or not. If the value is greater than unity high stress would be exerted by water on pipe. Field study has been made to collect water depth. Actual water depth is compared with determined water depth obtained from the model for dry weather flow. Discrepancy in depth between actual and model value ranges between 0.64 to $0.52 \mathrm{~m}$. This comparison reinforces the assessment of accuracy of the model value. This study will be helpful for understanding flow behavior for different discharge condition, as the pipe flow system is not accessible. Thus it is hoped that the study results can be useful to some extent for better management of post project storm drainage in the vicinity of the lake.

\section{REFERENCES}

[1] M. A. Matin and M. A. Rahman, "A scale model study of flow behavior of storm Diversion structure," in Proc. the National Seminar on Engineers Role in Developing Mega City, Institution of Engineers Bangladesh, December 2009, pp. 65-71

[2] M. A. Matin, T. Salauddin, and S. Sadeque, "Assessment of drainage capacity and navigability of Khals connecting Balu river of eastern part of Dhaka city," Bangladesh Journal of Water Resource Research, vol. 22, December 2010, pp. 41-53

[3] L. Malik, "Hydraulic analysis of storm diversion system of Begunbari Hatirjheel project," B.Sc. Engg. Thesis, Dept. of Water Resources Engineering, BUET, December 2014.

[4] Rajuk and Dwasa, "Integrated development of Hatirjheel area including parts of Begunbarikhal,” Mid Term Report, BRTC BUET, June 2008

[5] FAP 8B, "Study on storm water drainage system improvement project," Japan International Cooperation Agency (JICA), Main Report, 1990, Dhaka.

[6] V. T. Chow, Open Channel Hydraulics, McGraw Hill publishers, 1959.

[7] S. Afrin, M. M. Islam, and M. M. Rahman, "Development of IDF curve for Dhaka city based on scaling theory under future precipitation variability due to climate change," International Journal of Environmental Science and Development, 2014. 


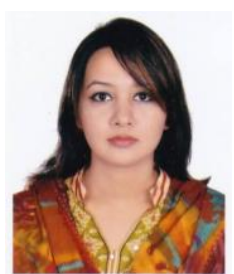

Lamisa Malik was born in Dhaka, Bangaldesh in January, 1990. She obtained her B.Sc. in engineering degree from Bangladesh University of Engineering and Technology (BUET) in 1990 and secured first position in order of merit. Ms Lamisa joined as a lecturer in the water resources engineering, BUET in 2014 and she is also pursuing her MSc. there. Her research interest are in water resources, hydraulics, river engineering, modeling, hydrology. Her undergraduate thesis was entitled "Hydraulic analysis of storm diversion system (SDS) of Hatirjeel Begunbari lake of Dhaka city".

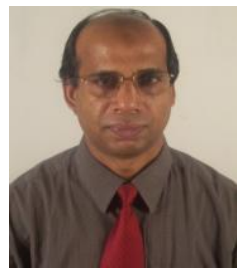

M. A. Matin was born in August 1958. M. A. Matin joined BUET in 1981. He is now working as a professor in Water Resources Engineering Department of BUET. He has vast knowledge and experience in the field of water resources engineering. Dr. Matin did his B.Sc. in civil engineering from BUET, the M.Sc.Engg from the same university in water resources engineering. He obtained his Ph.D in civil engineering (river eng.) degree from the University of Strathclyde, Glasgow, UK. Dr. Matin has already supervised significant numbers of PG research based theses. As a professional, Dr Matin involved in number of national level water related projects. He has vast research experience in the water related field and has around 65 publications in national and international Journals and proceedings. During his, career, Dr. Matin delivered lectures in water related subjects in many training courses organized by different water sector organizations as a resource person. 